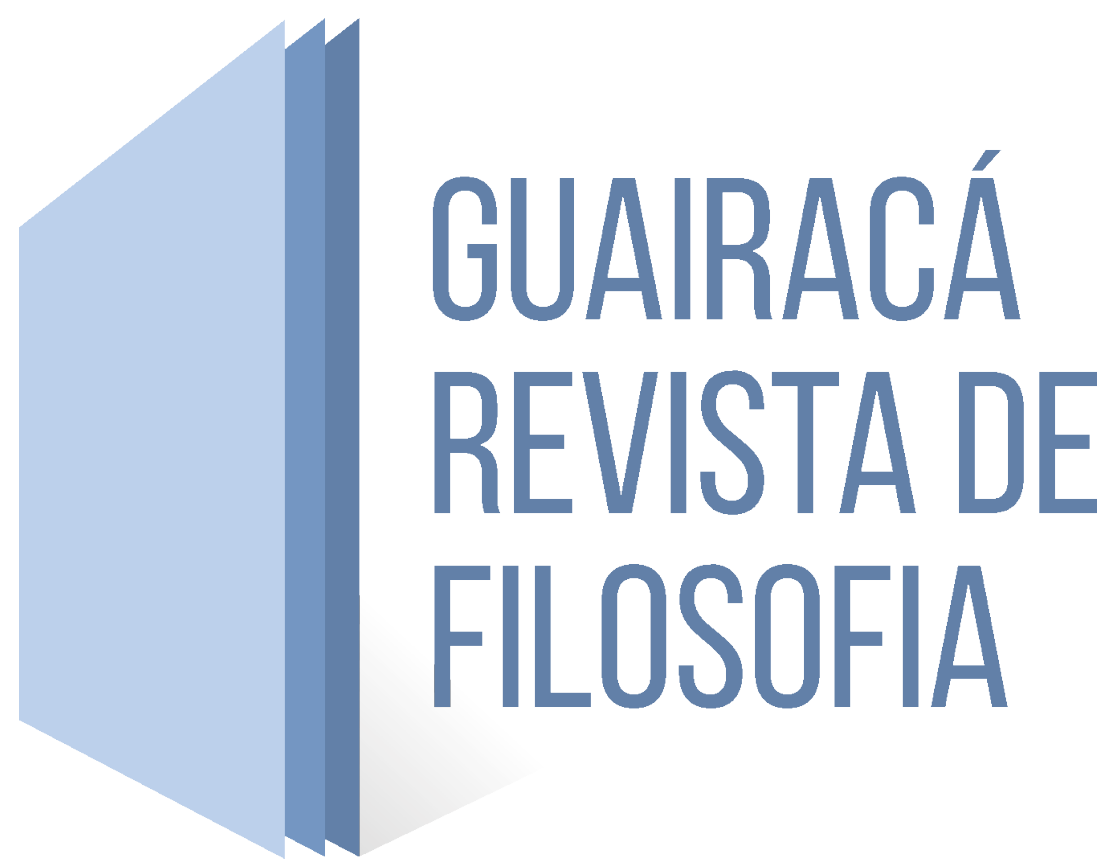

\title{
ARCHÉ PHILOSOPHIA: ALGUMAS REFLEXÕES SOBRE O CARÁTER E ORIGENS DA FILOSOFIA NO EM SEU PRIMEIRO TEMPO
}

Resumo: O objetivo do texto é apresentar uma visão da história da filosofia que se contrapõe às noções historial, de Heidegger, e teleológica de Hegel. Empreendemos isto a partir de uma releitura da problemática foucaultiana, especialmente da noção filosófica de estratégia que o filosófo francês apresenta em alguns textos. Assim, analisamos o surgimento da filosofia, especialmente Anaximandro e Heráclito, focalizando o uso que estes fazem de termoschave, como logos e arché, nodais para a tradição filosófica, mostrando como estes termos não podem ser desligados de um conflito que se processava na sociedade grega. Deste modo, damos estofo à noção estratégica de história da filosofia, a qual ora encontra-se em desenvolvimento.

Palavras-chave: História da filosofia. Teleologia. Historial. Estratégia.

1. Universidade Estadual Paulista" Júlio de Mesquita Filho" (UNESP). Email: gumapoldo51@ yahoo.com.br. 


\title{
ARCHÉPHILOSOPHIA: SOME REFLECTIONS ON THE CHARACTER AND ORIGINS OF PHILOSOPHY IN ITS FIRST TIME
}

\begin{abstract}
The objective of this text is to present a vision of philosophy's history that opposes to the historial, from Heidegger, and teleological, from Hegel. We do that departing from a rereading of the foucaldian problematic, specially the philosophical notion of strategy, which the French philosopher demonstrate in some texts. Therefore, we analyze the emergence of philosophy, specially Anaximander and Heraclitus, focusing the use of some keywords, like logos and arché, nodal to the philosophical tradition, showing how these terms cannot be disconnected from a conflict that was processing in the Greek society. This way, we give substance to the strategic notion of history of philosophy, which is under development.
\end{abstract}

Keywords: History of philosophy. Teleology. Historial. Strategy.

\section{O PROBLEMA DA ESTRATÉGIA}

Caso déssemos razão ao Monsieur Deleuze (DELEUZE,1997), nossa questão estaria equivocada desde a raiz, posto que nosso objetivo, na flor de nossa juventude, vem a ser formular um conceito de filosofia, universalmente aplicável a todas as filosofias particulares, a partir da análise da correlação de sua emergência. Este objetivo não deve ser confundido com a busca de um gênero de um fundamento de filosofia, que pressuporia um transcendente ou um transcendental ou, de outro modo dito, uma mesmidade repetindo-se ao longo do espaço-tempo. Trata-se, ao contrário, de analisar uma estratégia em seus desdobramentos táticos, uma estratégia que, enquanto tal, pertence a uma correlação de forças absolutamente particular. Precisamente, é nosso intuito afirmar que a filosofia deve ser entendida enquanto uma estratégia, exatamente, uma metaestratégia, de modo que este conceito, oriundo das pranchetas militares, deve ser tomado com uma seriedade somente vista em tempos de guerras profundas, posto que, através dele, pensamos ser capazes de dar conta dos principais problemas filosóficos que ora, talvez mesmo por sermos neófitos, nos deparamos. $\mathrm{O}$ que se deve entender por metaestratégia, qual a correlação na qual esta noção emergiu, e para onde ela aponta, eis o nosso objetivo neste curto ensaio. 
A noção de estratégia, de saída, parece impor alguns inconvenientes dos quais é mister desfazer-se. Um dos mais graves dentre eles é sua imediata, quase automática, referência a uma consciência (BEAUFRE, 2004). Em fato, termo de origem grega, como muitos outros da filosofia, relaciona-se ao strategós "general", ou a outros termos correlatos como strategís, "relativo ao general "ou stratia, "exército" (CHANTRAINE, 1968). A referência ao general, quer dizer, à consciência que concebe a estratégia, de onde que os termos liguem-se. A nosso turno intentamos conceber a noção de estratégia longe de uma consciência enquanto fundamento, porque intentamos fugir dessa mesma noção de fundamento - como se verá adiante.

Assim em nossa noção de estratégia está implícita que se trata de uma estratégia sem sujeito. É-nos impossível negar a origem deste conceito, como outros de nossa empreitada, na filosofia de Foucault (FOUCAULT, 1994). Este termo em específico aparece em alguns textos particulares, sem que o filósofo francês nele se aprofunde. Há, claro, o inconveniente de Foucault não ter desenvolvido seu pensamento genealógico da forma que gostaríamos, de modo que, ao tratar deste ponto, temos que interpretar - e Foucault teve razões fortes para não formular algo como um sistema clássico de filosofia, que pode ser resumido em sua recuso em formular algo como um foucaultianismo, ou, como diz Nietzsche em Ecce homo, no medo de se tornar santo (NIETZSCHE, 1995). Em fato, no texto que ora nos referimos, uma interlocutora de Foucault fala de uma estratégia sem sujeito, e a chamada do tópico trata de uma estratégia sem estrategista. O genealogista francês está se referindo às formas como se constituiu, paulatinamente, determinada hegemonia sobre a classe trabalhadora, no século XIX, na França, sem que, no entanto, esta forma particular de hegemonia tivesse sido pensada por ninguém.

Há elementos a se recuperar. Quando de então, Foucault está se valendo do método genealógico, cujo objetivo é analisar a formação de um caráter, em um quadro de luta generalizada, sem referência ao fundamento, constituindo, portanto, uma dupla relação de emergência em um gradil de forças, e de proveniência, na história de uma série de batalhas (FOUCAULT, 2001). O fundamento foi excluído: ele é dado na própria batalha, a qual, por sua vez, é dada em outra batalha, e assim vai - trata-se do que chamamos de dízima filosófica, ou, em outros termos, a constituição bélica transitória do caráter. Nestes marcos, podemos afirmar que, desde o ponto de vista que pergunta à política o que ela tem a dizer da lógica - em um novo giro copernicano - , de modo que de saída já há um objetivo estratégico na análise; enfim, podemos asseverar que se trata de uma lógica estratégica (FOUCAULT, 1999), cujo procedimento é o seguinte: o devir devem em uma correlação de forças. Esta correlação determina a existência dos objetos e, estando dada em certa correlação, esta existência é tática com implicações estratégicas, porque a tática contêm a estratégia: só se pode devir aquilo que a correlação permite. Deste modo, se escapa da referência a um sujeito que a fundamente, algo como um gênio estrategista, de 
onde o mundo decorreria; a correlação determina a existência das coisas (existir é estar em uma correlação, inclusive seu devir, quer dizer, sua estratégia). O devir torna-se, assim, o fluxo belicoso das táticas se justapondo em distintas correlações de força, e a estratégia nada mais seria senão a determinação do devir do objeto ao constituí-lo em uma correlação de forças.

Vê-se, portanto, que ao invés de fundamentar-nos na consciência, ou em qualquer outra coisa, nós mesmos determinamos que este objeto, consciência, constitui-se em uma correlação de forças. E também determinamos que a determinação da determinação da consciência como se constituindo em uma correlação de forças constituição em uma correlação de forças - trata-se de outra dízima filosófica. Nestes marcos, existir é tático com implicações estratégicas. E a constituição deste pensamento só pode ser pensada em uma correlação de forças: em tal geografia, com tal história, etc, as quais, cada qual a seu turno, constituíramse em correlações de força - o mundo de tal feita constituído desfalece nos conflitos que o formam, e seu devir há de ser resolvido em outra série de conflitos. Emerge, pois, ao primeiro plano filosófico uma disciplina obscura, quase obliterada, a filosofia da guerra.

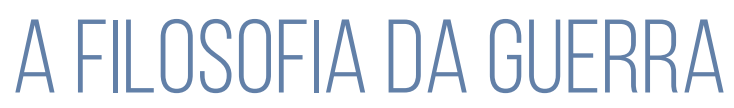

Isto tudo, de um lado. De outro temos que um dos inconvenientes do termo estratégia é que ele parece não ser de estirpe filosófica, antes sendo mais afeito seja às ciências políticas, ao marketing e, claro, à ciência militar. Dentro do campo filosófico a disciplina ou especialidade mais afeita à noção de estratégia seria a filosofia da guerra, acima referida. Trata-se de uma bibliografia magra, a nosso ver escassamente desenvolvida, embora seja de idade respeitável (ECEME, s/d). Em fato, se considerarmos por filosofia da guerra a reflexão de determinados sujeitos, os filósofos, sobre a guerra, iremos longe, posto que desde Heráclito o termo guerra é corrente em filosofia, e desde Platão ao menos se pode encontrar este positivo "guerra" como objeto da reflexão filosófica. Contudo, é en general, Clausewitz, que se pode encontrar a reflexão maior, sistemática, sobre a guerra no Ocidente; isto não quer dizer, que não existam outros tratados militares, mas Clausewitz é sua expressão maior (LUIZ, 2014).

Alguns, talvez por pureza ou por certo instinto de classe, não queiram dar a Clausewitz um estatuto de filósofo, e, no fundo, esta pertença pouco importa. Encontramos em seus escritos um conceito universal de guerra e bem como seu papel em um estado. Para nós, o fato de Clausewitz trabalhar com estas noções qualifica seu pensamento como de estirpe filosófica, e, se há uma disciplina chamada filosofia da guerra, mais ou menos aparentada com a filosofia política e com a ética, o 
pensamento de Clausewitz deve constar em seu programa, juntamente com Platão, Aristóteles, Maquiavel, Kant, dentre outros.

Passa longe, contudo, de nosso escopo, elaborar uma filosofia da guerra neste sentido estrito: um objeto guerra positivo, com suas espécies, sobre a qual desenvolver-se-á certo tipo de reflexão, a filosófica. Antes pretendemos interpretar a filosofia nos marcos da guerra, mas exatamente, enquanto uma estratégia, precisamente, uma metaestratégia (LUIZ, 2017). De fato, alguns estudos (LUIZ, 2014) apontam que há dois outros usos da temática guerra em filosofia (possivelmente, não os únicos), um metafórico, sobre o qual tornaremos alhures, outro ontometodológico, que discorremos a seguir.

Fizemos referências a Heráclito de Éfeso, e não à toa. No pensamento do Efésio encontra-se a guerra (pólemos) tematizada em dois fragmentos diferentes. De modo geral, aponta-se Heráclito como tendo formulado uma ontologia realista nos marcos do primeiro tempo da reflexão filosófica (CRESSON, 1960), quer dizer, tratar-se-ia, como aponta Aristóteles, de um fisiólogo (ARISTÓTELES, 986b). Há característica especiais na ontologia heraclítica, posto que se trata de uma tal que assume o devir, sendo por isso constantemente oposta a ontologia imobilista de Parmênides e da escola eleática. Outros apontam, contudo, que este traço mobilista não deve ser creditado ao Efésio, já se encontrando no pensamento de Anaximandro. É nos marcos de uma ontologia mobilista, que aponta, no entanto, o fogo como arché das coisas, que Heráclito tematiza a guerra. Em um dos fragmentos lê-se que guerra é pai de todas as coisas (DK 53); noutra que a guerra é comum a tudo (DK 80). Ela seria, portanto, correlata ao fogo, cumprindo um papel de princípio (arché) do universo (kosmos). A guerra seria destarte ontológica, coextensiva à mobilidade universal que cobre tudo. Na mesma linha heraclítica, se situa o pensamento de Hegel, que faz reverências críticas ao Efésio, e, por extensão, o de Marx, bem como toda a tradição marxista. Tornaremos sobre este ponto, pontuando diferenças e simitudes, e, também problemas.

Há, também, Foucault. Neste, encontramos a constituição de um modelo de análise de poder, de um método, pautado na guerra. Já o pincelamos acima: trata-se de compreender as relações de poder como autofundantes, transitórias e específicas, em um gradil de forças, assumindo que há certa lógica de funcionamento do mundo e esta é a do combate entre as forças. Foucault chama em alguns textos este posicionamento de lógica estratégica, mas parece não tê-la desenvolvido. Em todo caso, marque que este tematização da guerra dá-se em um quadro de uma epistemologia política mobilista que assume o conflito como lógica das coisas - e não uma ontologia, portanto, como nós mesmos mais acima desenhamos.

Ao buscarmos elaborar uma análise da filosofia enquanto guerra, devemos, pois, agir à moda estratégica; logo, compete-nos conhecer o terreno sobre o qual 
vamos nos mover. Consideraremos, pois, a existência de três tipos de discurso: as belicidades, que assumem a existência da guerra ontometodologicamente, caso do pensamento de Foucault; as falsas-belicidades, que assumem só parcialmente pressupostos bélicos, caso do marxismo; e as não-belicidades, que não assumem a guerra senão como algo estritamente militar.

Precisemos: uma belicidade parte de pressupostos bélicos (ontológicos metodológicos, ontometodológicos) e desenvolve suas análises nestes marcos. Inclusive, se situa neste gradil de forças, de modo que o próprio pensamento que pensa a guerra é colocado em uma correlação de forças que a explica. Tratese de situar-se na correlação na qual se está inserindo. Se bem o pensamento de Foucault enquadre-se aqui, ele sofre do grave mal de não produzir, ele mesmo, uma estratégia, ou bem, de sua estratégia ser inteiramente negativa: mostrar a formação das estratégias, sem dar, ele mesmo, os pressupostos de outra estratégia. Certamente, é polêmico os motivos que levaram Foucault a não elaborar, ele mesmo esta estratégia. Contudo, note-se que, em sendo a estratégia fundamentalmente sem sujeito, quer dizer, como ela emerge em um correlação de forças, há uma estratégia em curso. Resta precisá-la, corrigi-la, enfim, pôr-se na luta.

Consideramos Heráclito, Hegel e Marx falsamente bélicos. Em fato, são realistas, quer dizer, encontra-se em seu pensamento a asserção de verdades fundamentais fora de uma correlação: eles não se explicam pela correlação até as últimas conseqüências. Em Heráclito usa o termo pólemos, e não outras palavras gregas que designam o conflito, com ligeira mudanças de significado, como pále ou agón; um destes termos, stásis, que indica dissenção, faria com que o conflito que é "pai de todas as coisas" não fosse externo, como o pólemos indica, mas interno, no coração de tudo quanto há; em outros termos, as coisas entre si discordam, mas acordam no coração do ser. Em Hegel, a seu turno, encontramos primeiramente, a identificação entre lógica e ser, de modo que os movimentos do ser são lógicos, e podem, assim, ser deduzidos de seu princípio (Anfang), este se impõe sobre as coisas, com uma lei de ferro determinando não só sua constituição íntima, mas seu movimento necessário rumo a dada finalidade, de modo que, nesta história dedutiva, se bem há suprassunção, ela é subsunção, ou redução ao elemento do mesmo; quer dizer, o disparate entre as coisas não é conseqüente, é falso. No marxismo, isto aparece na própria ideia de um socialismo científico, que acedeu à verdade, em contraposição a consciência mistificada pela ideologia; e também na ideia que a história é redutível a uma forma fundamental, que termina por reduzir os conflitos; ou na própria idéia de que os acontecimentos são redutíveis a um fundo comum determinante.

A maior parte dos discursos, no entanto, é constituída de não-belicidades. Assumem a existência de fundamentos mais ou menos estáveis, e a guerra é reduzida 
ao fenômeno stricto senso de duas nações, povos ou tribos em combates campais. Não se toma o conflito, mas o contrato, por exemplo; assume-se a existência de uma natureza humana; pensa-se na existência de transcendentais, etc.

Nosso intuito, portanto, é constituir uma belicidade. Isto implicar tanto tomar as coisas belicamente, como também nos colocarmos em certa estratégia. Afinal, o que decorre do fato da filosofia ser entendida como estratégia? Para onde aponta este posicionamento? E de onde ele vem?

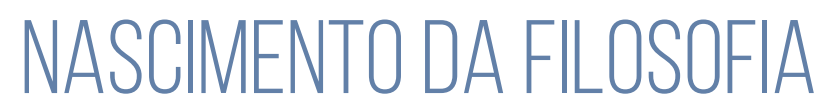

Esta análise deve nos conduzir, pois, à correlação de forças na qual surge a filosofia. Ou seja, a pergunta pelo quid é uma pergunta pelo situs. De modo geral, põe-se a filosofia em contraste com o mito, o que nos parece correto. Em Hesíodo, onde se encontra a mitologia sistematizada, há certas determinações estratégicas fundamentais: de onde veio o mundo, para onde ele vai, quais forças o dominam, o que é licíto, o que é ilícito, como proceder. Trata-se do desenho de uma sociedade, que especifica um themis, quer dizer, certas coisas vetadas ou permitidas pela vontade divina; há a Moira, a parte de cada um no universo, a hybris, a ultrapassagem desta parte, e a nemesis, a vingança divina por exceder o que é próprio a cada um. Isto deve ser entendido no seio das mudanças pelas quais passava a sociedade grega homérica, na qual as forças que projetavam o mundo clássico já se faziam sentir (PRATES E SILVA, 1992). A própria filosofia, tendo surgido nas colônias, decorrentes da exigüidade de terras a se cultivar e da concentração fundiária, nas quais as melhores terras estavam com os pater genos, já indica as estratégias em conflito. Devese marcar que a ruptura com a racionalidade mitológica poetizadora e o surgimento da racionalidade filosófica em prosa indicam diferentes determinações do vir-a-ser da sociedade em uma correlação de forças.

Em fato, com Tales, e mais ainda, com Anaximandro, primeira filosofia que podemos analisar, posto que dela temos fragmentos, surge uma nova racionalidade. A filosofia milésia surge em um contexto de reformadores por todo o mundo grego, estando no centro do problema a questão na terra. A própria noção de lei, ou, mais exatamente, do que é lícito fazer, themis, cai, emergindo a noção de nómos, cujo significado primitivo é relacionado à divisão de terras, e devemos salientar os parentescos com nemein, o verbo pastar. Anaximandro introduzirá a noção de que existe uma totalidade ordenada, um kósmos, por um princípio, arché; que as coisas advêm desta arché e para ela hão de retornar, pois tem um determinado tempo de vida, durante o qual sua origem desta arché determina os traços fundamentais de sua existência. Porque o princípio concebido enquanto arché não é um princípio em geral, mas um muito específico, tendo em vistas que outras palavras do grego 
poderiam marcar a ideia de princípio, mas Anaximandro, que introduziu o termo arché, o escolheu especificamente. Arché vem do verbo archein que significa também "comandar", "ser o chefe", "mandar", "governar"; e arché pode significar ao mesmo tempo que "começo", "império". Trata-se, pois, de uma modalidade bem marcada de começo, um tal que reverbera sobre aquilo que começou, que continua a exercer influência mesmo quando já se deitou o tempo sobre as coisas. E é exatamente no tempo que este começo comandante se exerce sobre as coisas, como nos diz a sentença de Anaximandro.

Há claro, variadas questões interpretativas sobre a sentença de Anaximandro, por vezes beirando o meramente técnico. Ressaltamos que ele utiliza um vocabulário jurídico, mais propriamente utilizado nos trâmites judiciais, como díke, tisin, taxin, adikias. De qualquer forma, a ideia de um começo enquanto aquilo que comanda, enquanto um fundamento da existência da coisa marcou-se profundamente no pensamento filosófico, e seus ecos são sentidos até hoje. Decorre dele, ou the são aparentados, outras noções que a doxografia informa serem próximas de Anaximandro, como noção de que as coisas têm um ciclo (kuklos) de existência. Neste milésio há também a ideia de que há um determinado fim, expresso no grego pela palavra telos, a qual, se bem não apareça na sentença, subjaz ao seu pensamento, posto que as coisas dirigem-se a dado termo. Há uma ordem do mundo, um kosmos, termo de múltiplos sentidos, mas que indica um arranjo bem feito das coisas, uma vez que o termo relaciona-se ao verbo kosméo, que é "arrumar em boa disposição", "por em uma boa ordem", guardando também o sentido subreptício de "comandar", "governar"; o kosmos não se restringe às coisas que hoje chamaríamos naturais, as coisas da physis; esta distinção entre natural e humano é posterior; poderíamos dizer que o pensamento do milésio aplica-se ao conjunto do existente, não somente à natureza.

Anaximandro formula, pois, um pensamento que afirma o princípio que comanda originando o kosmos, ditando-lhe certas prescrições de existência, que são punidas se desrespeitadas, mas que, de toda forma, determinam o próprio encaminhamento do mundo. Anaximandro formula o devir das coisas, as enquadra: lhes dá uma estratégia ele mesmo. Ao pretender formular o devir do mundo, a filosofia pretende nos entregar uma estratégia do começo, desenrolar e fenecer do existente (LUIZ, 2018). Por isso chamamos esta abordagem de filosofia da guerra.

Em Heráclito, estes elementos serão desenvolvidos e majorados. Além de utilizar também o conceito de kosmos, Heráclito introduz o termo logos, polissêmico, de ampla significação. O logos relaciona-se a pelo menos dois verbos diferentes, legō, "dizer" e logísdomai, "calcular", "contar", "raciocinar". O aoristo (passado) de lego é éipon. Pode-se fazer certas relações entre o eipon e o epos, o discurso da épica, quer dizer, Homero, Hesíodo - que narram um mundo mitificado, povoado de 
deuses. Epos tem muitos sentidos, um dos quais, precisamente, o de ser a fala de um deus ou oráculo. Ao afirmar, portanto, que há um logos do kosmos ao qual é preciso se atentar, em primeiro lugar deve-se entender seu pensamento estritamente nos marcos de uma intenção antirreligiosa, contra os mitos (BERGE, 1969). Há muitas referências a esta violência contra a tradição nos fragmentos. Por exemplo, ele reverencia Bías de Priene, um dos setes sábios da Grécia. Bias, contudo, é um nome que guarda parentesco com biazdein, "ser violento", "violentar"; ou senão, o fato dele ter depositado seu texto junto à estátua de Diana, deusa da caça. Heráclito está escrevendo contra a tradição.

Ademais, a escolha do fogo como arché, e da guerra como coextensiva ao kosmos; tudo isto dá a medida de seus objetivos belicosos. Heráclito, contudo, não parece aplicar seus pressuposto sobre si mesmo: se a guerra é "pai de todas as coisas" ou se "ela é comum", tudo se dando segundo a discórdia; o pensamento que pensa isto também é, portanto, belicoso, se situa na guerra. Heráclito, contudo, embora traga em si os pressupostos belicosos, não os desenvolve, o que não o deixa de situar como um formulador de certa estratégia.

\section{FLLOSOFIA COMO METAESTRATÉGIA}

Há, destarte, no próprio vocabulário dos primeiros filósofos, certa carga estratégica; e a colocação de novos princípios de compreensão em um mundo regulado pela religião dão mostras do quão estratégica foi a filosofia. A religião, pois, parece ter sido o adversário primeiro da filosofia. Filosofia é um nome, portanto, de uma estratégia, ou antes, de uma metaestratégia, posto que compreende, em seu seio, variadas estratégias distintas, unidas, contudo, nesta busca pelo fundamento que comanda, arché.

Por este motivo não é lícito falar em filosofia fora do Ocidente, por exemplo. Isto porque é um metaestratégia específica, na miríade outras plasmáveis; enquanto tal, deve ser situada. No pensamento chinês, por exemplo, encontram-se outras estratégias, outros pressupostos e objetivos; e mesmo o Tao, que pareceria ser um gênero de arché, não tem como fundo a ideia do comando sobre o mundo como tem seu análogo grego (CHOW, 1961). Querer reduzir as outras estratégias à filosofia é, em fato, um tipo de imperialismo ocidental sobre os outros povos, querendo reduzir outras racionalidades à razão ocidental. Em suma, é mister dar às coisas seus nomes.

A compreensão da filosofia como metaestratégia se opõe imediatamente à compreensão teleológica e à compreensão historial, que são, a seu turno, estratégias. A compreensão teleológica supõe um fim para a filosofia, em um processo de desenvolvimento lógico, necessário, ignorando, desta feita, as correlações de força que estabeleceram este processo; ademais, toma uma espécie de razão como o modelo, 
e intenta estabelecê-lo como apodítico. Doutro lado, a compreensão historial parte da noção da distinção entre a origem e o desenrolar da filosofia, como se uma queda tivesse se desenvolvido; esta queda teria determinado que a filosofia voltasse-se para os entes em prejuízo de uma reflexão sobre o ser, determinando, portanto, o advento da técnica; contudo, como se viu, a concepção que intenta dominar já se mostra na aurora da filosofia, é-lhe constitutiva.

Uma concepção metaestratégica da filosofia não só dá-lhe as distintas correlações ao longo do espaço-tempo, como também, forçosamente, deve descobrir o objetivo estratégico da filosofia, bem como as táticas para ele. Quer dizer, que se expressou como objetivo da filosofia e como ela intenta alcançá-lo. Disto, contudo, temos poucas pistas, e uma nova pesquisa precisa ser empreendida a fim de estabelecê-lo.

\section{BIBLIOGRAFIA}

ARISTÓTELES; Metafísica, SP: Loyola, 2002

BEAUFRE, A; Introdução à estratégia, Lisboa: Silabo, 2004

BERGE, D.; O logos heraclítico: introdução à leitura dos fragmentos, RJ: Instituto Nacional do Livro/MEC, 1969

CHANTRAINE, P.; Dictionnaire étymologique de la langue grecque. Histoire des mots, Paris: Klincksieck, 1968

CHOW, Y-C; La philosophie chinoise, Paris: PUF, 1961, 2ª ed.

CRESSON, A.; A filosofia antiga, SP: Difusão Européia do Livro, 1960, 2a edição

DELEUZE, G.; O que é filosofia?, RJ: 34, 1997, 2ª ed.

ECEME; Introdução à estratégia, disponível em http://www.eceme.eb.mil.br/images/ cpeceme/publicacoes/Introd Estrat11.pdf, acessado dia 11/03/2019

FOUCAULT, M.; Dits et écrits I 1954-1975 v. I, Paris: Gallimard, 2001

- Dits et écrits 1976-1979 v. III, Paris: Gallimard, 1994

; Em defesa da sociedade, SP: Martins Fontes, 1999

LUIZ, F.; Anaximandro, a teleologia e a história, Diaphonía, v. 4, n. 2, 2018, disponível em http://e-revista.unioeste.br/index.php/diaphonia/article/view/21309/13590, acessado em 20/03/2019 
; Filosofia como estratégia, Diaphonía, v. 3, n. II, 2017, disponível em http://erevista.unioeste.br/index.php/diaphonia/article/view/18641/12265, acessado em 20/03/2019

;O fragmento 53 DK de Heráclito de Éfeso, no prelo.

; Precisões sobre o conceito de filosofia da guerra, Filogênese, Marília-SP, vol. 7, no. 2, 2014, disponível em

http://www.marilia.unesp.br/Home/RevistasEletronicas/FILOGENESE/2 felipeluiz.pdf., acessado em 20/03/2019

NIETZSCHE, F.; Ecce homo: como alguém se torna o que é, SP: Cia das Letras, 1995

PRATES E SILVA, R. C. B. A justiça cósmica (um estudo sobre Anaximandro de Mileto), Tese de Livre-docência, Araraquara: FCL-UNESP, 1992 